\title{
Prognostic role of TPL2 in early-stage non-small cell lung cancer
}

\author{
LAURA BOLDRINI ${ }^{1}$, MIRELLA GIORDANO ${ }^{1}$, ADELE SERVADIO $^{1}$, CRISTINA NICCOLI $^{1}$, \\ PIETRO BERTOGLIO ${ }^{1}$, MARCO LUCCHI $^{1}$, FRANCA MELFI $^{2}$, ALFREDO MUSSI $^{1}$ and GABRIELLA FONTANINI $^{1}$
}

${ }^{1}$ Department of Surgical, Medical, Molecular Pathology and Critical Care, University of Pisa;
${ }^{2}$ Unit of Thoracic Surgery, Azienda Ospedaliero-Universitaria Pisana, I-56126 Pisa, Italy

Received July 19, 2016; Accepted November 9, 2016

DOI: $10.3892 / \mathrm{mmr} .2017 .6430$

\begin{abstract}
Non-small cell lung cancer (NSCLC) accounts for $\sim 70 \%$ of all lung cancer-associated mortalities worldwide. The serine/threonine protein kinase tumor progression locus 2 [TPL2/MAP3 kinase 8 (MAP3K8)] may impact oncogenic events; however the role of TPL2 in lung carcinogenesis remains unclear. The present study was focused on the potential prognostic role of TPL2 in 101 patients with early-stage NSCLC. Since TPL2 is a potential target of $m i R-21$, the association between TPL 2 and $m i R-21$ expression was also examined. TPL2 and $m i R-21$ mRNA expression was quantified using reverse transcription quantitative polymerase chain reaction (RT-qPCR). TPL2 protein levels were evaluated by immunohistochemistry (IHC). The present study identified that the mRNA expression of TPL2 was low in 52/101 (51\%) cases and high in 49/101 (49\%) cases. IHC analysis of TPL2 protein expression often demonstrated identical mRNA results. No statistically significant associations were observed between the mRNA expression of TPL2 and the predominant clinicopathological characteristics of the patients with NSCLC, as well as identifying no association between TPL2 and miR-21. TPL2 mRNA expression was significantly higher in patients with NSCLC with good prognosis (disease-free interval $\mathrm{P}=0.009$; overall survival $\mathrm{P}=0.024$ ), when compared with those of poor prognosis. Focusing on the difference in mRNA expression of TPL2 among the adenocarcinomas in affected patients, TPL2 was more highly expressed in lepidic adenocarcinomas compared with in the other subtypes $(\mathrm{P}=0.012)$. The present study is the first examination, to the best of our knowledge, of TPL2 in early-stage NSCLC in relation to $m i R-21$, and in different adenocarcinoma subtypes. Future studies must clarify the mechanism by which TPL2 is involved in lung carcinogenesis due to its important translational implications.
\end{abstract}

Correspondence to: Dr Laura Boldrini, Department of Surgical, Medical, Molecular Pathology and Critical Care, University of Pisa, 10 Via Savi, I-56126 Pisa, Italy

E-mail: laura.boldrini@med.unipi.it

Key words: tumor progression locus 2, non-small cell lung cancer, lung adenocarcinoma subtype, $m i R N A-21$, prognosis

\section{Introduction}

Although surgical intervention is effective for the majority of early-stage non-small cell lung cancer (NSCLC), 20-30\% of patients experience relapses (1). Therefore, the identification of prognostic markers and novel therapeutic targets is of crucial importance. The serine/threonine protein kinase tumor progression locus 2 [TPL2/MAP3 kinase 8 (MAP3K8)] acts as an essential signal for the expression of pro-inflammatory mediators in several cell systems, including peripheral macrophages (2), adipocytes (3), hepatic stellate cells (4), airway epithelial cells (5) and glial cells (6). Inflammatory molecules have emerged as significant in the development of cancer, with roles in events leading to the formation, growth and metastasis of tumors. TPL2 has been suggested to enhance tumor growth and metastatic progression in distinct types of human cancer (7-9). Overexpression of TPL2 has been reported in human gastric/colon adenocarcinomas (10), large granular T-cell neoplasias (11) and breast cancer $(12,13)$. However, a detailed evaluation of TPL2 expression and function in human malignancies and normal tissues remains to be performed, and the role of TPL2 in carcinogenesis remains unclear. TPL2 may stimulate oncogenic events, including the cellular response to therapy and immune control of cancer growth (14). However, in certain cases, TPL2 may function as a tumor suppressor (15). Little information regarding the prognostic role of TPL2 in the oncogenesis of NSCLC exists to assist with identifying those at high-risk of relapse following surgical resection.

Several previous studies have identified micro (mi) RNAs as critical regulators of immune responses, including inflammation $(16,17)$. Mechanistically, miRNAs are small, non-coding RNA molecules that pair with partially complementary sequences in their target mRNAs and regulate their stability and/or translation. Extracellular signals, differentiation and oncogenic transformation bring about alterations in the expression of miRNAs, allowing miRNAs to regulate these processes. Previous studies have suggested that $m i R-21$ overexpression may be an independent negative prognostic factor in the overall survival of patients with NSCLC (18), and that $m i R-21$ targets numerous genes involved in cancer cell phenotypes (19). Using three miRNA target identification programs (miRNAorg, MicroCosm Targets and PITA), $T P L 2$ was identified among the potential targets of $m i R-21$. Therefore, the present study was based on the analysis of the 
potential association between TPL2 and miR-21 in cases of early-stage NSCLC.

\section{Materials and methods}

Patients. A total of 101 patients with NSCLC at peripheral stage I (T1N0M0) underwent surgical resection in the Unit of Thoracic Surgery in the Department of Surgical, Medical, Molecular Pathology and Critical Care at Pisa University (Pisa, Italy), and were retrospectively selected. Histological diagnoses were formulated by two pathologists independently (G.F. and A.S.), in accordance with the World Health Organization classification $(20,21)$. Clinicopathological characteristics were noted in all cases. Written informed consent was obtained from each patient for tissue collection and molecular analysis.

Target prediction. Alignment of miRNAs with the TPL2 target gene was predicted using the microRNA target prediction programs microRNA.org (Harvard Medical School, Boston, MA, USA), MicroCosm Targets 5.0 (The European Bioinformatics Institute) and PITA (Weizmann Institute of Science).

RNA isolation. Following standard deparaffinization and manual tumor macrodissection of the areas with prevalent adenocarcinomas, the miRNeasy formalin-fixed and paraffin-embedded (FFPE) kit (Qiagen GmbH, Hilden, Germany) was used to isolate total RNA, including miRNAs, from $5 \mu \mathrm{m}$ sections of FFPE tissues, according to the manufacturer's protocol. A total of $600 \mathrm{ng}$ of total RNA was used to synthesize cDNA using the RevertAid First Strand cDNA Synthesis kit (Thermo Fisher Scientific, Inc., Waltham, MA, USA) in a reaction volume of $20 \mu \mathrm{l}$.

Expression of TPL2 $\mathrm{mRNA}$ and $\mathrm{miR}-21$ using the reverse transcription quantitative-polymerase chain reaction (RT-qPCR). Quantification of the mRNA expression of TPL2 was performed in triplicate using the Rotor Gene SYBR Green PCR kit (Qiagen GmbH) on a Rotor Gene 6000 (Qiagen $\mathrm{GmbH}$ ). The following primers used for RT-qPCR are as follows: TPL2, forward: 5'-TAATCCACAAGCAAGCAC CTC-3' and reverse: 5'-TGATTGGGGTTTCTCTCCAG-3'); $\beta$-actin, forward: 5'-CCAACCGCGAGAAGATGA-3' and reverse: 5'-CCAGAGGCGTACAGGGATAG-3'. Specific TaqMan ${ }^{\circledR}$ MicroRNA assays (Applied Biosystems; Thermo Fisher Scientific, Inc.) were used to amplify $m i R-21$ and $R N U 6 B$, according to the manufacturer's protocol. In addition, the threshold cycle and baselines were determined in an identical manner. The expression was calculated by relative quantification using $\beta$-actin and $R N U 6 B$ as reference controls for TPL2 and $m i R-21$, respectively. Fold expression changes were determined by the $2^{-\Delta \Delta \mathrm{Cq}}$ method (22) using a pool of 12 non-cancerous tissues as a calibrator group. The analysis was performed using the DataAssist ${ }^{\mathrm{TM}}$ software (Applied Biosystems; Thermo Fisher Scientific, Inc.).

Protein expression of TPL2. The protein expression of TPL2 was assessed in FFPE tissue samples using immunohistochemistry (IHC). The Cot (M-20) anti-TPL2 rabbit polyclonal antibody (dilution, 1:50; cat. no. sc-720, Santa Cruz
Biotechnology, Inc., Dallas, TX, USA) was incubated at $37^{\circ} \mathrm{C}$ for $36 \mathrm{~min}$ to detect the protein. The avidin-biotin peroxidase method was used by developing the immunoreaction with diaminobenzidine. Simultaneous staining of a known TPL2-positive case was used as a positive control. Incubation of parallel slides omitting the first antibody was performed as a negative control. The number of TPL 2 immunoreactive cells was determined by scoring a minimum of five high-power fields (magnification, x40) and counting the number of immunoreactive cells out of the total epithelial cells analyzed in each field of view.

A proportion score (PS) was assigned by representing the estimated proportion of positively stained cells, and was divided into three groups: negative (score 0), 1-60\% (score 1) and $>60 \%$ (score 2 ). An intensity score (IS) was also assigned and divided into four classes: None (score 0), weak (score 1), intermediate (score 2) and strong (score 3). A total score was obtained from the sum of the PS and IS, and was graded into two classes: High (4-5, with a higher expression of TPL2) and low (0-3, with a lower or negative TPL2 expression).

Statistical analysis. One-way analysis of variance and chi-squared tests were used to determine the association between the expression of TPL2, miR-21 levels and the clinicopathological parameters. Survival analyses were performed using the Kaplan-Meier method, along with the log-rank test and the Cox proportional hazard model. Statistical analyses were performed using the JMP10 software (SAS Institute, Inc., Cary, NC, USA). $\mathrm{P}<0.05$ was considered to indicate a statistically significant difference.

\section{Results}

Patient characteristics. The present study was performed using 101 patients with early-stage NSCLC (71 males and 30 females), including 54 patients with adenocarcinoma (ADC) and 47 patients with squamous cell carcinoma (SCC). Regarding their histological classification, different histological subtypes of ADC were identified: Acinar (19/54, $35.2 \%)$, lepidic $(18 / 54,33.3 \%)$, mucinous $(9 / 54,16.7 \%)$, papillary $(6 / 54,11.1 \%)$ and solid $(2 / 54,3.7 \%)$. The median age at diagnosis was 67 years (range, 49-81; mean, 67.03 years), and the median follow-up was 63 months (range, 6-161 months). In terms of tumor grade, five tumors were G1 phase, 71 tumors were G2 phase and 25 were G3 phase. Disease progression and mortality from lung cancer were observed in 27 patients with ADC (26.7\%) and 20 with SCC (19.8\%) of the 101 patients with NSCLC, respectively. The median progression-free survival and the overall survival were 54 months (95\% CI: 6-161) and 68 months (95\% CI: 11-161), respectively. Regarding smoking habits of the entire patient group, there were 15 non-smokers, 44 former smokers and 42 current smokers (Table I).

TPL2 expression and clinicopathological characteristics. TPL2 mRNA expression was quantified in 101 NSCLC tissues and in 12 non-cancerous tissues, and was normalized against the $\beta$-actin housekeeping gene, using RT-qPCR. The samples were divided into high and low expression groups based on the median fold-change value (0.815 for TPL2). TPL2 mRNA expression was low in 52/101 (51\%) cases and 
Table I. Correlation between the mRNA expression of tumor progression locus 2 and the predominant clinicopathological characteristics of patients with early-stage non-small cell lung cancer.

\begin{tabular}{|c|c|c|c|}
\hline \multirow[b]{2}{*}{ Characteristic } & \multicolumn{2}{|c|}{ TPL2 expression } & \multirow[b]{2}{*}{$\mathrm{P}$-value } \\
\hline & Low \% & High \% & \\
\hline Age, years & & & 0.368 \\
\hline$\leq 67$ & $24(47.1)$ & $27(52.9)$ & \\
\hline$>67$ & $28(56.0)$ & $22(44.0)$ & \\
\hline Gender & & & 0.809 \\
\hline Male & $36(50.7)$ & $35(49.3)$ & \\
\hline Female & $16(53.3)$ & $14(46.7)$ & \\
\hline Histology & & & 0.471 \\
\hline Adenocarcinoma & $26(48.1)$ & $28(51.9)$ & \\
\hline Squamous cell carcinoma & $26(55.3)$ & $21(44.7)$ & \\
\hline Smoking history & & & 0.512 \\
\hline Never & $6(40.0)$ & $9(60.0)$ & \\
\hline Former & $25(56.8)$ & $19(43.2)$ & \\
\hline Current & $21(50.0)$ & $21(50.0)$ & \\
\hline Tumor grade & & & 0.661 \\
\hline $\mathrm{G} 1$ & $3(60.0)$ & $2(54.5)$ & \\
\hline $\mathrm{G} 2$ & $38(53.5)$ & $33(46.5)$ & \\
\hline G3 & $11(44.0)$ & $14(56.0)$ & \\
\hline
\end{tabular}

high in 49/101 (49\%) cases (data not shown). The present study determined whether TPL2 expression was correlated with the predominant clinicopathological characteristics. No statistically significant associations were observed between TPL2 mRNA expression and any of the predominant clinicopathological characteristics of the patients with NSCLC (Table I). However, focusing on the difference in TPL2 levels among the different subtypes of the 54 adenocarcinomas, it was identified that TPL2 mRNA expression was high in 6/19 (31.6\%) acinar, 13/18 (72.3\%) lepidic, 5/9 (55.6\%) mucinous, 3/6 (50\%) papillary and $1 / 2(50 \%)$ solid subtypes, with a significantly higher level in lepidic when compared with all other subtypes (Chi-squared test, $\mathrm{P}=0.012$; data not shown).

Using the 2-level (high/low) immunohistochemical scoring system, TPL2 protein expression was low in 45/101 (44\%) and high in 56/101 (56\%) cases (Fig. 1). Even if the correlation between the level of TPL2 mRNA and the score of its protein was not significant (chi-squared test, $\mathrm{P}=0.36$ ), samples with a low TPL 2 protein score expression typically exhibited lower mRNA levels $(2.33$-fold change value \pm 1.55$)$

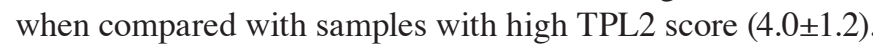
In addition, a high score for TPL2 protein was identified in the lepidic adenocarcinoma subtype $(\mathrm{P}=0.003)$, as aforementioned for TPL2 mRNA expression.

Target prediction and correlation between TPL2 and miR-21 expression. Alignment of miRNAs with the TPL2 target mRNA was predicted by the miRNA target prediction programs miRBase, MicroCosm Targets and PITA. The present study identified the TPL2 gene as a potential target of $m i R-21$ (Fig. 2). Firstly, the patients with NSCLC were divided into $m i R-21$ high and low expression groups based on the median fold change values, which resulted as 1.7. Following this, the present study determined whether TPL2 expression was correlated with $m i R-21$ levels, but no statistically significant associations were observed between groups (Chi-squared test, $\mathrm{P}=0.66$ ).

Survival analysis. To evaluate the potential association between TPL2 expression and the prognosis of the patients with NSCLC, a survival analysis by the Kaplan-Meier method using the disease-free interval (DFI) and the overall post-operative survival (OS) as endpoints was performed. It was noted that the tumors with a high TPL2 mRNA expression demonstrated a significantly longer mean DFI and OS compared with the patients with low expression of this mRNA ( $\mathrm{P}=0.009$ and $\mathrm{P}=0.024$, respectively; Fig. 3 and Table II). In the multivariate analysis, TPL2 mRNA expression continued to be a good prognostic factor for DFI and OS $(\mathrm{P}=0.0005$ and $\mathrm{P}=0.005$; Table II). Tumor grading, a classical prognostic factor, was also associated with the DFI in the univariate $(\mathrm{P}=0.0019)$ and multivariate analyses $(\mathrm{P}=0.0008$; Table II $)$, as well as with the $\mathrm{OS}(\mathrm{P}=0.0009$ and $\mathrm{P}=0.0002$, respectively). No significant differences were identified for other demographics or clinical characteristics (Table II). Furthermore, the median DFI and OS were similar in examined patients with either low or high $m i R-21$ expression (data not shown).

Following this analysis, the survival difference between the histological cell types was investigated. No significant difference was observed between SCC and ADC (Table II). However, based on the difference of the TPL2 levels reported above, the NSCLCs were divided into three prognostic groups: Squamous cell carcinoma and the two predominant adenocarcinoma growth patterns (acinar and lepidic subtypes). The group with the most favorable prognosis was the lepidic predominant subtype, which was demonstrated earlier in the study to possess a higher level of TPL2, with a median DFI of 85 months and a median OS of 90 months. SCC and acinar ADC, both NSCLC tumors with lower TPL2 levels, presented a worse prognosis with a mean DFI of 53 and 68 months and with a mean OS of 65 and 68 months, respectively $(\mathrm{P}=0.02$ and $\mathrm{P}=0.03$; Fig. 4).

\section{Discussion}

TPL2 is involved in numerous intracellular signaling pathways, with a prominent role in the regulation of inflammatory signal transduction (2-6). TPL2 may be able to engage a plethora of signaling pathways and to act in concert with other kinases and signaling molecules. A major role of TPL2 is in the activation of the ERK/MAPK pathway through the direct phosphorylation of MEK, an extracellular signal-regulated kinase, which is a pro-inflammatory mediator. Conversely, in certain disease models, TPL2 deficiency exacerbates the inflammatory response (23). The diverse and often contradictory effects of TPL2 may be due to the utilization of different kinases and signal transduction pathways in different cell types. Similar contradictory data concerning the role of TPL2 in oncogenic signal transduction exist in the literature. 
A

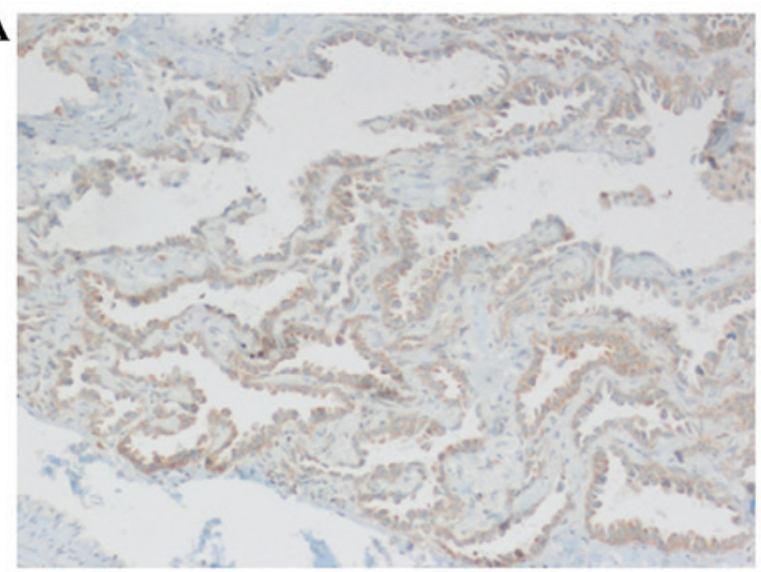

C

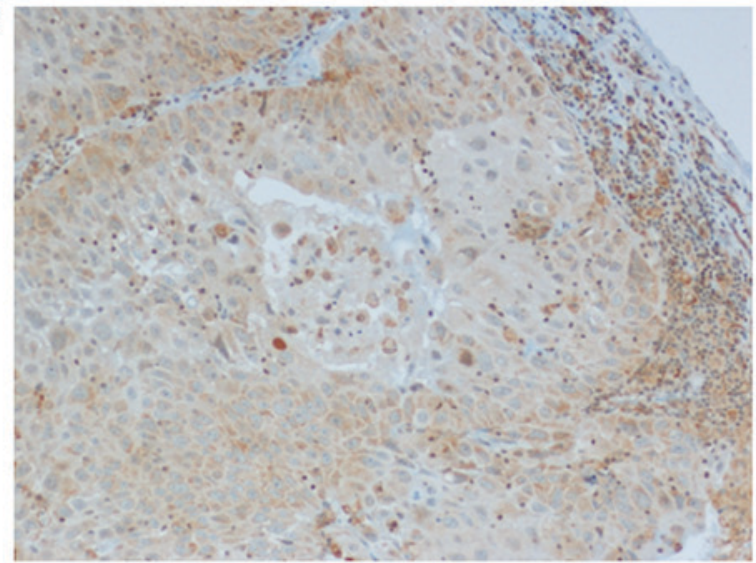

B

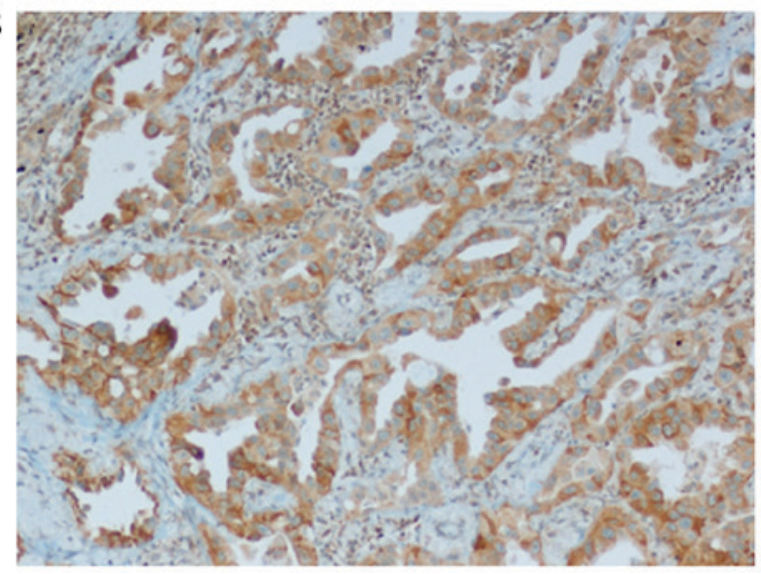

D

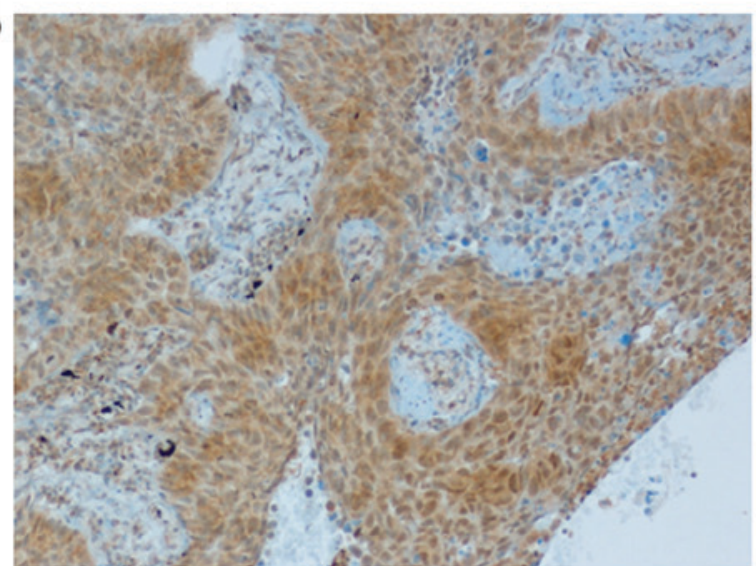

Figure 1. Immunohistochemical staining of tumor progression locus 2 in adenocarcinomas with (A and B) lepidic prevalent pattern and (C and D) squamous cell carcinoma, with low level positive staining shown on the left and high level positive staining on the right (magnification, x10).

\section{3’ agUUGUAGUCAGACUAUUCGAu 5’ hsa-miR-21 || || | $\quad|||||| \mid$}

\section{8: 5’ ugAAGAUUGUAGCAAUAAGCUg 3' MAP3K8}

Figure 2. miR-21 alignment with tumor progression locus 2 (MAP3K8) mRNA. The alignment of miR-21 with tumor progression locus 2 was determined using the miRBase target prediction program.

Gkirtzimanaki et al (15) demonstrated a tumor suppressor function for TPL2 in lung cancer. However, in contrast, elevated levels of TPL2 have been reported in several tumor types (10-13). TPL2 inhibitors are currently in advanced pharmaceutical development for the treatment of myeloma (24). The effects of inhibiting different MAP kinases may have different consequences in a cell-type-dependent manner, and therefore, any therapeutic use of kinase inhibitors must be carefully considered.

Considering these discrepancies, the aim of the present study was to elucidate the role of TPL2 in lung cancer, specifically in early-stage NSCLC. NSCLC accounts for $~ 70 \%$ of all lung cancer-associated mortalities worldwide (25). The current standard of care for stage I NSCLC is surgery; however, $20-30 \%$ of these early-stage patients will experience recurrence (1), reflecting the urgent requirement to develop adjunctive, specific markers that can aid in the prognosis of lung cancer. In the present report, it was demonstrated that low TPL2 mRNA levels correlated with reduced survival in TNM stage I lung cancer patients, suggesting loss of its expression was an early event in the development of the disease. Immunohistochemical analysis of TPL2 protein expression confirmed the corresponding mRNA results, even if not fully. There are presumably several reasons for a weak correlation between mRNA and protein levels, including mRNA post-transcriptional modifications, translational efficiency, miRNA actions and errors in both mRNA and protein measuring techniques. In addition, due to subcellular localization, TPL2 protein abundance may not represent its biological activity.

It was later hypothesized that TPL2 may be correlated with miRNAs, which are small, non-coding RNAs that regulate target gene expression $(26,27)$. Several miRNAs are aberrantly expressed in the majority of human cancer types (19). Oncogenes and tumor suppressor genes exert their activity, in part, by regulating the expression of specific miRNAs (28). 
Table II. Factors associated with disease-free survival in patients with early-stage non-small cell lung cancer.

\begin{tabular}{lcc}
\hline Characteristic & Univariate analyses (P-value) & Multivariate analyses (P-value) \\
\hline Age ( 667 vs. >67 years) & 0.7107 & 0.7141 \\
Gender (male vs. female) & 0.0866 & 0.4067 \\
Histology (ADC vs. SCC) & 0.1030 & 0.9908 \\
Smoking (current/former vs. never) & 0.5915 & 0.5477 \\
Tumor grading (G1 vs. G2/G3) & 0.0019 & 0.0008 \\
TPL2 mRNA level (low vs. high) & 0.0009 & 0.0005
\end{tabular}

ADC, adenocarcinoma; SCC, squamous cell carcinoma; TPL2, tumor progression locus 2.
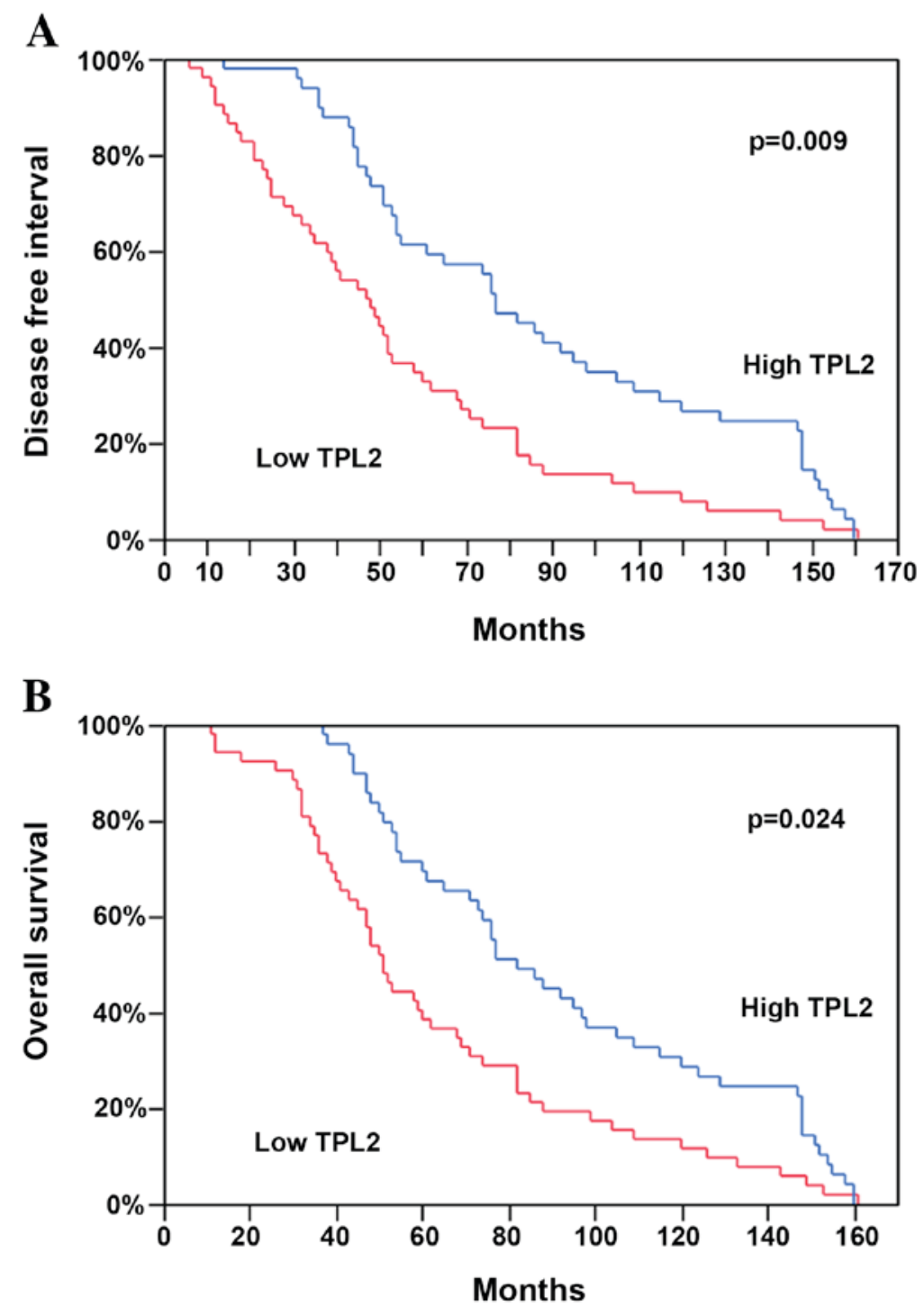

Figure 3. Kaplan-Meier curves of patients with early-stage non-small cell lung cancer. Kaplan-Meier curves for the survival analysis of (A) DFI and (B) OS in 101 patients with early-stage non-small cell lung cancer with high (blue line) or low (red line) TPL2 expression. High TPL2 mRNA expression demonstrated a significantly longer mean DFI and OS when compared to the patients with low expression of this mRNA $(\mathrm{P}=0.009$ and $\mathrm{P}=0.024 \mathrm{vs}$. low TPL2 mRNA expression). TPL2, tumor progression locus 2; DFI, disease free interval; OS, overall survival.

miR-21 has proven to be a useful prognostic indicator in numerous cancer types, including NSCLC $(29,30)$. Using the miRNA target prediction programs miRBase, MicroCosm Targets and PITA, the present study identified TPL2 as a potential target of $m i R-21$. As a result, the study evaluated $m i R-21$ expression in early-stage NSCLC and its association with TPL2 levels by combining miR-21 expression with TPL2 levels. The present study is the first, to the best of our 

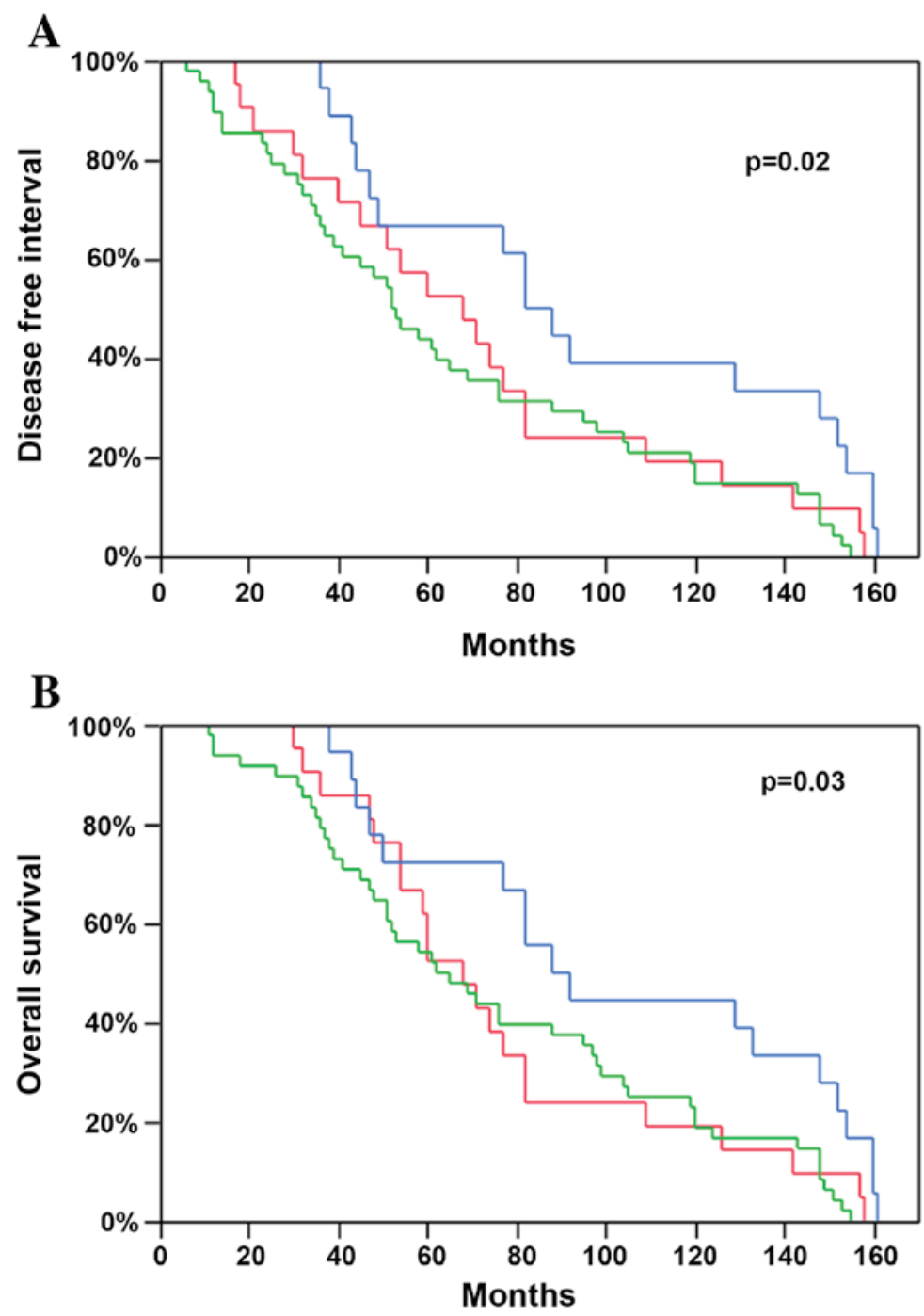

Figure 4. Kaplan-Meier curves of patients with SCC, acinar ADC and lepidic ADC subtype. Kaplan-Meier curves for the survival analysis of (A) DFI and (B) OS in patients with SCC (green line), acinar ADC (red line) and lepidic (blue line) ADC subtypes. The lepidic subtype possessed a higher median DFI and OS than the acinar subtype and SCC ( $\mathrm{P}=0.02$ and $\mathrm{P}=0.03$ vs. SCC). DFI, disease free interval; OS, overall survival; SCC, squamous cell carcinoma.

knowledge, to test the hypothesis that $m i R-21$ may cooperate with TPL2. It was revealed that TPL2 levels were not correlated with $m i R-21$, suggesting no association between $m i R-21$ and TPL2 in lung carcinogenesis. In addition, no difference in the disease prognosis was observed for $m i R-21$ in the present cases, as also previously reported by the authors (31). The prognostic role of this miRNA is controversial, whilst certain studies have demonstrated that $m i R-21$ overexpression is associated with poor NSCLC survival $(18,32,33)$, other studies have indicated a converse or insignificant association $(34,35)$. In view of the present results, the prognostic role of TPL2 is independent from the expression of $m i R-21$.

Furthermore, histological subtyping has been proposed as a potential screening tool to identify the patients with lung cancer at a high risk for recurrent disease and an unfavorable prognosis (36). In the comparisons between the patients with adenocarcinoma and squamous cell carcinoma, ADCs with a lepidic pattern exhibited significantly improved survival. Although this prognosis of lepidic adenocarcinoma (37-39), and the more aggressive course of the disease and poor prognosis in the SCC histotype (40) have been well-documented, the finding of the lepidic ADC pattern correlation with high TPL2 expression has been not previously reported. Squamous cell lung carcinoma, even if clearly biologically different from the adenocarcinoma histotype, may behave as an adenocarcinoma arising from a non-terminal respiratory unit that is centrally originated, solid in morphology, poorly differentiated and often necrotic (41).

TPL2 appears to have divergent roles in different cells and tissues, serving as an oncogene as well as a tumor suppressor gene. In addition, how TPL2 acts in carcinogenesis remains to be elucidated. Gkirtzimanaki et al (15) hypothesized that TPL 2 may lead to increased accumulation and activation of p53, resulting in an accelerated cell death and reduced malignant transformation. This hypothesis is corroborated by the good prognosis of lung cancer patients bearing tumors with elevated levels of TPL2, as it was identified in early-stage NSCLCs. Downregulation of TPL2, as a result of a genetic or epigenetic alteration, including $\mathrm{LOH}$, overexpression of miRNAs, or oncogenic RAS signaling, depending upon the histological subtype, may have an impact on the early stages of human lung disease similar to 
the effects of TPL2 ablation on lung cancer initiation in the mouse (15).

In conclusion, the present study is the first examination, to the best of our knowledge, of the association between TPL2 and early-stage lung carcinogenesis, underscoring its tumor suppressor gene role. In the present analysis, $m i R-21$ expression did not impact on TPL2 expression. Future studies must involve an analysis of TPL2 in advanced lung cancer stages and its downstream signaling. In addition, studies must correlate findings with other miRNA expression profiles to clarify the mechanism by which TPL2 is involved in lung carcinogenesis, taking into consideration all histological subtypes, and any important translational implications.

\section{References}

1. Hoffman PC, Mauer AM and Vokes EE: Lung cancer. Lancet 355: 479-485, 2000

2. Dumitru CD, Ceci JD, Tsatsanis C, Kontoyiannis D, Stamatakis K, Lin JH, Patriotis C, Jenkins NA, Copeland NG, Kollias G and Tsichlis PN: TNF-alpha induction by LPS is regulated posttranscriptionally via a TPL2/ERK-dependent pathway. Cell 103: 1071-1083, 2000.

3. Jager J, Gremeaux T, Gonzalez T, Bonnafous S, Debard C, Laville M, Vidal H, Tran A, Gual P, Le Marchand-Brustel Y, et al: TPL2 kinase is upregulated in adipose tissue in obesity and may mediate interleukin-1beta and tumor necrosis factor-\{alpha\} effects on extracellular signal-regulated kinase activation and lipolysis. Diabetes 59: 61-70, 2010.

4. Perugorria MJ, Murphy LB, Fullard N, Chakraborty JB, Vyrla D, Wilson CL, Oakley F, Mann J and Mann DA: Tumor progression locus $2 /$ Cot is required for activation of extracellular regulated kinase in liver injury and toll-like receptor-induced TIMP-1 gene transcription in hepatic stellate cells in mice. Hepatology 57: $1238-1249,2013$

5. Martel G, Bérubé $\mathrm{J}$ and Rousseau S: The protein kinase TPL2 is essential for ERK1/ERK2 activation and cytokine gene expressionin airway epithelial cells exposed to pathogen-associated molecular patterns (PAMPs). PLoS One 8: e59116, 2013.

6. Hirschhorn J, Mohanty S and Bhat NR: The role of tumor progression locus 2 protein kinase in glial inflammatory response. J Neurochem 128: 919-926, 2014.

7. Yu YP, Landsittel D, Jing L, Nelson J, Ren B, Liu L, McDonald C, Thomas R, DhirR, Finkelstein S, et al: Gene expression alterations in prostate cancer predicting tumor aggression and preceding development of malignancy. J Clin Oncol 22: 2790-2799, 2004.

8. Hatziapostolou M, Polytarchou C, Panutsopulos D, Covic L and Tsichlis PN: Proteinase-activated receptor-1-triggered activation of tumor progression locus- 2 promotes actin cytoskeleton reorganization and cell migration. Cancer Res 68: 1851-1861, 2008

9. Yang Y, Wang X, Hawkins CA, Chen K, Vaynberg J, Mao X, Tu Y, Zuo X, Wang J, Wang YX, et al: Structural basis of focal adhesion localization of LIM-only adaptor PINCH by integrin-linked kinase. J Biol Chem 284: 5836-5844, 2009.

10. Ohara R, Hirota S, Onoue H, Nomura S, Kitamura Y and Toyoshima K: Identification of the cells expressing cot proto-oncogene mRNA. J Cell Sci 108: 97-103, 1995.

11. Christoforidou AV, Papadaki HA, Margioris AN, Eliopoulos GD and Tsatsanis C: Expression of the TPL2/Cot oncogene in human T-cell neoplasias. Mol Cancer 3: 34, 2004.

12. Sourvinos G, Tsatsanis C and Spandidos DA: Overexpression of theTpl-2/Cot oncogene in human breast cancer. Oncogene 18: 4968-4973, 1999.

13. Krcova Z, Ehrmann J, Krejci V, Eliopoulos A and Kolar Z: Tpl-2/Cot and COX-2 in breast cancer. Biomed Pap Med Fac Univ Palacky Olomouc Czech Repub 152: 21-25, 2008.

14. Lee HW, Joo KM, Lim JE, Cho HJ, Cho HJ, Park MC, Seol HJ, Seo SI, Lee JI, Kim S, et al: TPL2 kinase impacts tumor growth and metastasis of clear cell renal cell carcinoma. Mol Cancer Res 11: 1375-1386, 2013.

15. Gkirtzimanaki K, Gkouskou KK, Oleksiewicz U, Nikolaidis G, Vyrla D, Liontos M, Pelekanou V, Kanellis DC, Evangelou K, Stathopoulos EN, et al: TPL2 kinase is a suppressor of lung carcinogenesis. Proc Natl Acad Sci USA 110: E1470-E1479, 2013
16. Baltimore D, Boldin MP, O'Connell RM, Rao DS and Taganov KD: MicroRNAs: New regulators of immune cell development and function. Nat Immunol 9: 839-845, 2008.

17. Xiao C and Rajewsky K: MicroRNA control in the immune system: Basic principles. Cell 136: 26-36, 2009.

18. Gao W, Yu Y, Cao H, Shen H, Li X, Pan S and Shu Y: Deregulated expression of miR-21, miR-143 and miR-181a in non small cell lung cancer is related to clinicopathologic characteristics or patient prognosis. Biomed Pharmacother 64: 399-408, 2010.

19. Volinia S, Calin GA, Liu CG, Ambs S, Cimmino A, Petrocca F, Visone R, Iorio M, Roldo C, Ferracin M, et al: A microRNA expression signature of human solid tumors defines cancer gene targets. Proc Natl Acad Sci USA 103: 2257-2261, 2006.

20. Travis WD, Brambilla E, Noguchi M, Nicholson AG, Geisinger KR, Yatabe Y, Beer DG, Powell CA, Riely GJ, Van Schil PE, et al: International association for the study of lung cancer/American thoracic society/European respiratory society international multidisciplinary classification of lung adenocarcinoma. J Thorac Oncol 6: 244-85, 2011.

21. Travis WD, Brambilla E, Noguchi M, Nicholson A, Geisinger K, Yatabe Y, Ishikawa Y, Wistuba I, Flieder DB, Franklin W, et al: Diagnosis of lung cancer in small biopsies and cytology: Implications of the 2011 international association for the study of lung cancer/American thoracic society/European respiratory society classification. Arch Pathol Lab Med 137: 668-684, 2013.

22. Livak KJ and Schmittgen TD: Analysis of relative gene expression data using real-time quantitative PCR and the 2-(Delta Delta C(T)) method. Methods 25: 402-408, 2001

23. Decicco-Skinner KL, Trovato EL, Simmons JK, Lepage PK and Wiest JS: Loss of tumor progression locus 2 (tpl2) enhances tumorigenesis and inflammation in two-stage skin carcinogenesis. Oncogene 30: 389-1397, 2011.

24. Asimakopoulos F, Kim J, Denu RA, Hope C, Jensen JL, Ollar SJ, Hebron E, Flanagan C, Callander N and Hematti P: Macrophages in multiple myeloma: Emerging concepts and therapeutic implications. Leuk Lymphoma 54: 2112-2121, 2013.

25. Siegel R, Naishadham D and Jemal A: Cancer statistics, 2012. CA Cancer J Clin 62: 10-29, 2012.

26. Krol J, Loedige I and Filipowicz W: The widespread regulation of microRNA biogenesis, function and decay. Nat Rev Genet 11: 597-610, 2010.

27. Schetter AJ, Heegaard NH and Harris CC: Inflammation and cancer: Interweaving microRNA, free radical, cytokine and p53 pathways. Carcinogenesis 31: 37-49, 2010.

28. Fujita K, Mondal AM, Horikawa I, Nguyn GH, Kumamoto K, Sohn JJ, Bowman ED, Mathe EA, Schetter AJ, Pine SR, et al: p53isoforms Delta133p53 and p53beta are endogenous regulators of replicative cellular senescence. Nat Cell Biol 11: 1135-1142, 2009.

29. Saito M, Schetter AJ, Mollerup S, Kohno T, Skaug V, Bowman ED, Mathé EA, Takenoshita S, Yokota J, Haugen A and Harris CC: The association of microRNA expression with prognosis and progression in early-stage, non small cell lung adenocarcinoma: A retrospective analysis of three cohorts. Clin Cancer Res 17: 1875-1882, 2011

30. Yanaihara N, Caplen N, Bowman E, Seike M, Kumamoto K, Yi M, Stephens RM, Okamoto A, Yokota J, Tanaka T, et al: Unique microRNA molecular profiles in lung cancer diagnosis and prognosis. Cancer Cell 9: 189-198, 2006.

31. Capodanno A, Boldrini L, Proietti A, Alì G, Pelliccioni S, Niccoli C, D'Incecco A, Cappuzzo F, Chella A, Lucchi M, et al: Let-7g and miR-21 expression in non-small cell lung cancer: Correlation with clinicopathological and molecular features. Int J Oncol 43: 765-774, 2013.

32. Liu XG, Zhu WY, Huang YY, Ma LN, Zhou SQ, Wang YK, Zeng F, Zhou JH and Zhang YK: High expression of serum miR-21 and tumor miR-200c associated with poor prognosis in patients with lung cancer. Med Oncol 29: 618-626, 2012.

33. Gao W, Shen H, Lui L, Xu J, Xu J and Shu Y: MiR-21 overexpression in human primary squamous cell lung carcinoma is associated with poor patient prognosis. J Cancer Res Clin Oncol 137: 557-566, 2011.

34. Markou A, Tsaroucha EG, Kaklamanis L, Fotinou M, Georgoulias V and Lianidou ES: Prognostic value of mature microRNA-21 and microRNA-205 overexpression in non-small cell lung cancer by quantitative real-time RT-PCR. Clin Chem 54: 1696-1704, 2008 
35. Voortman J, Goto A, Mendiboure J, Sohn JJ, Schetter AJ, Saito M, Dunant A, Pham TC, Petrini I, Lee A, et al: MicroRNA expression and clinical outcomes in patients treated with adjuvant chemotherapy after complete resection of non-small cell lung carcinoma. Cancer Res 70: 8288-8298, 2010.

36. Gu J, Lu C, Guo J, Chen L, Chu Y, Ji Y and Ge D: Prognostic significance of the IASLC/ATS/ERS classification in Chinese patients-A single institution retrospective study of 292 lung adenocarcinoma. J Surg Oncol 107: 474-480, 2013.

37. Russell PA, Wainer Z, Wright GM, Daniels M, Conron M and Williams RA: Does lung adenocarcinoma subtype predict patient survival?: A clinic-pathologic study based on the new international association for the study of lung cancer/American thoracic society/European respiratory society international multidisciplinary lung adenocarcinoma classification. J Thorac Oncol 6: 1496-1504, 2011.
38. Solis LM, Behrens C, Raso MG, Lin HY, Kadara H, Yuan P, Galindo H, Tang X, Lee JJ, Kalhor N, et al: Histological patterns and molecular characteristics of lung adenocarcinoma associated with clinical outcome. Cancer 118: 2889-2899, 2012.

39. Araki K, Kidokoro Y, Hosoya K, Wakahara M, Matsuoka Y, Takagi Y, Haruki T, Miwa K, Taniguchi Y, Horie S and Nakamura H: Excellent prognosis of lepidic-predominant lung adenocarcinoma: Low incidence of lymphatic vessel invasion as a key factor. Anticancer Res 34: 3153-3156, 2014.

40. Okamoto T, Maruyama R, Suemitsu R, Aoki Y, Wataya H, Kojo M and Ichinose Y: Prognostic value of the histological subtype in completely resected non-small cell lung cancer. Interact Cardiovasc Thorac Surg 5: 362-366, 2006.

41. Yatabe Y, Mitsudomi T and Takahashi T: TTF-1 expression in pulmonary adenocarcinomas. Am J Surg Pathol 26: 767-773, 2002. 